\title{
Controlled CVD growth of highly $<111>$-oriented 3C-SiC
}

Jing-Jia Huang, ${ }^{a, b}$, Christian Militzera.b, Charles Wijayawardhana ${ }^{b}$, Urban Forsberg ${ }^{a}$, Lars Ojamäe ${ }^{a}$, Henrik Pedersen ${ }^{a *}$

a Department of Physics, Chemistry and Biology, Linköping University, SE-581 83 Linköping, Sweden

${ }^{b}$ SGL Carbon GmbH, Drachenburgstraße 1, DE-53170 Bonn, Germany

* Corresponding author: henrik.pedersen@liu.se

\begin{abstract}
Highly <111>-oriented 3C-SiC coatings with distinct surface morphology consisting of hexagonally shaped pyramidal crystals were prepared by chemical vapor deposition (CVD) using silicon tetrachloride $\left(\mathrm{SiCl}_{4}\right)$ and toluene $\left(\mathrm{C}_{7} \mathrm{H}_{8}\right)$ at $\mathrm{T} \leq 1250{ }^{\circ} \mathrm{C}$ and $\mathrm{p}=10 \mathrm{kPa}$. In contrast, similar deposition conditions, using methane $\left(\mathrm{CH}_{4}\right)$ as carbon precursor, resulted in randomly oriented 3C-SiC coatings with a cauliflower-like surface of SiC crystallites. No excess carbon was detected in the highly $<111>$-oriented $3 \mathrm{C}$-SiC samples despite the use of aromatic hydrocarbons. The difference in the preferred growth orientation of the $3 \mathrm{C}-\mathrm{SiC}$ coatings deposited using $\mathrm{C}_{7} \mathrm{H}_{8}$ and $\mathrm{CH}_{4}$ as carbon precursors is explained via quantum chemical calculations of binding energies on various crystal planes. The adsorption energy of $\mathrm{C}_{6} \mathrm{H}_{6}$ on the SiC (111) plane was 6 times higher than that on the (110) surface. On the other hand, the $\mathrm{CH}_{3}$ exhibited equally strong adsorption on both planes. This suggests that the highly $<111>-$ oriented $3 \mathrm{C}$-SiC growth in the $\mathrm{C}_{7} \mathrm{H}_{8}$ process, where both $\mathrm{C}_{6} \mathrm{H}_{6}$ and $\mathrm{CH}_{3}$ are considered the main active carbon-containing film forming species, is due to the highly preferred adsorption on (111) planes, while the lower surface energy of the (110) plane controls the growth orientation in the $\mathrm{CH}_{4}$ process, in which only $\mathrm{CH}_{3}$ contributes to the film deposition.
\end{abstract}




\section{INTRODUCTION}

Polycrystalline silicon carbide $(\mathrm{SiC})$ is a protective coating of choice in many industries due to its high chemical inertia, hardness and temperature stability. Among SiC polytypes, cubic $\mathrm{SiC}$, also known as $3 \mathrm{C}$ - or $\beta$-SiC, is the most used in refractory applications due to its relatively low formation temperature. One of the techniques frequently adopted for the synthesis of polycrystalline $3 \mathrm{C}$-SiC is chemical vapor deposition $(\mathrm{CVD})^{1}$. In a SiC CVD process, multicomponent precursors, e.g. methyl trichlorosilane, can assure unity of $\mathrm{C} / \mathrm{Si}$ ratio in the gas phase, whereas singe-component precursors containing only $\mathrm{C}$ or Si can grant the process extra degrees of freedom in choosing different $\mathrm{Si}$ - and C-source precursors ${ }^{2}$. Chlorinated silanes, especially silicon tetrachloride $\left(\mathrm{SiCl}_{4}\right)$ are widely used precursors in many SiC processes. The addition of $\mathrm{Cl}$ to the SiC CVD processes has been reported to not only increase the growth rate but also prevent the formation of Si droplets in the gas phase. The stronger $\mathrm{Si}-\mathrm{Cl}$ bonds $(400 \mathrm{~kJ} / \mathrm{mol})^{3}$ can suppress the formation of weaker Si-Si bonds $(226 \mathrm{~kJ} / \mathrm{mol})^{3,4}$. In terms of the C-source precursor, branched and small hydrocarbons such as ethylene or propane are often used since they can produce high-quality SiC coatings and are available at high purities.

As in many polycrystalline materials, the physical and chemical properties of $3 \mathrm{C}$-SiC coatings are dependent on the crystalline orientation. It has been shown that the Vickers microhardness of <111>-oriented 3C-SiC films, i.e. films in which the (111) planes were aligned parallel to the surface, was higher than those $<110>$-oriented ${ }^{5}$. The $(110)$ and (111) planes are the two planes in $3 \mathrm{C}$-SiC with the lowest surface energy; $3.4 \mathrm{~J} / \mathrm{m}^{2}$ and $4.2 \mathrm{~J} / \mathrm{m}^{2}$, respectively ${ }^{6}$. In the $\mathrm{SiCl}_{4}$-based $3 \mathrm{C}$-SiC CVD processes, the preferred growth orientation of resultant coatings varies with the selection of hydrocarbons as well as the deposition conditions. It was reported that using $\mathrm{CH}_{4}$ as carbon source, highly $<111>$-oriented $3 \mathrm{C}$-SiC can be produced either at $\mathrm{T}=1200{ }^{\circ} \mathrm{C}, \mathrm{p}_{\text {tot }}=4 \mathrm{kPa}^{7}$ or at $1200<\mathrm{T} \leq 1500^{\circ} \mathrm{C}, \mathrm{p}_{\text {tot }} \geq 40 \mathrm{kPa}^{8}$. On the other hand, at $\mathrm{T}=1450{ }^{\circ} \mathrm{C}, \mathrm{p}_{\text {tot }}=1 \mathrm{kPa}$ or at $\mathrm{T}>1450{ }^{\circ} \mathrm{C}, \mathrm{p}_{\text {tot }} \leq 10 \mathrm{kPa}$, highly $<110>$-oriented $3 \mathrm{C}$-SiC was obtained ${ }^{8}$. Similarly, with $\mathrm{C}_{3} \mathrm{H}_{8}$ as carbon source, the growth at $\mathrm{T}=1200{ }^{\circ} \mathrm{C}, \mathrm{p}_{\text {tot }}=$ $4 \mathrm{kPa}$, was highly $<111>$-oriented, but switches to $<110>$ at elevated temperatures ${ }^{7,9}$. No explanation for these changes in preferred growth orientation was suggested in these studies. Highly $<111>$-oriented $3 \mathrm{C}$-SiC has also been prepared with hexamethyldisilane via laser 
CVD ${ }^{10-14}$. However, due to the small laser spot size, the coating area was limited to less than $20 \times 20 \mathrm{~mm}$.

Although it appears that small aliphatic hydrocarbons are favored in 3C-SiC CVD, presumably owing to their relatively simpler structures, the use of aromatics as carbon precursor in CVD of other metal carbides has been reported. Nagai et al. deposited $\beta-\mathrm{Mo}_{2} \mathrm{C}$ thin films using benzene as carbon precursor ${ }^{15}$, whereas toluene was used for the deposition of $\mathrm{SiC}$ reported by Zhuravlov et $\mathrm{al}^{16}$. $\mathrm{TiC}_{\mathrm{x}}$ was prepared both from benzene $\mathrm{e}^{17}$ and toluene $\mathrm{e}^{18}$. However, either amorphous carbon or pyrolytic graphite was detected in most of these carbide films. Despite the risk of carbon co-deposition, the use of aromatic hydrocarbons as carbon precursor may also influence the preferred growth orientation of deposited films. In the work of Leonhardt et al., a transition of preferred growth orientation from $<100>$ to $<111>$ with the change of carbon precursors from aliphatic, e.g. methane, to aromatic hydrocarbons, e.g. benzene, was observed in the growth of $\mathrm{TiC}_{\mathrm{x}}$. This phenomenon was later interpreted by Pedersen et al. through quantum chemical calculations where they claimed that the adsorption energy of benzene molecules on $\mathrm{TiC}(111)$ surfaces was higher than that on $\mathrm{TiC}(100)$, resulting in a $<111>$-oriented growth, whereas methane molecules did not exhibit preferential adsorption on either surfaces, and therefore the TiC would preferentially grow on the surface that has the lowest surface energy, i.e. (100) in $\mathrm{TiC}^{19}$. While both $\mathrm{TiC}$ and $3 \mathrm{C}$ $\mathrm{SiC}$ are face-centered cubic crystal systems, TiC adopts the rock-salt structure, (B1, No. 225), and $3 \mathrm{C}-\mathrm{SiC}$ the zincblende structure, (B3, No. 216). Despite their structural difference, the crystal plane along $<111>$ direction in both crystals is terminated only with either $\mathrm{C}$ or $\mathrm{Si} / \mathrm{Ti}$ atoms. This indicates that the (111) planes of $\mathrm{TiC}$ and $3 \mathrm{C}-\mathrm{SiC}$ may exhibit similar properties for adsorbing molecules; therefore, the growth direction of $3 \mathrm{C}-\mathrm{SiC}$ can possibly be steered in the same way as in the growth of TiC.

In this work, we test this hypothesis and demonstrated the possibility of controlling the preferred growth orientation of polycrystalline 3C-SiC between $<111>$ and $\langle 110\rangle$ by using either toluene or methane as carbon precursors in $\mathrm{SiCl}_{4}$-based $\mathrm{SiC} \mathrm{CVD}$. Furthermore, by quantum chemical calculations we show how the adsorption behavior of benzene and methyl group differs when they approach the 3C-SiC (111) and (110) surfaces. 


\section{METHODS}

Film deposition. 3C-SiC coatings were deposited on isostatic graphite substrates $(100 \mathrm{~mm}$ x $60 \mathrm{~mm} \times 1.5 \mathrm{~mm}$ ) via a horizontal hot-wall chemical vapor deposition (CVD) reactor using silicon tetrachloride $\left(\mathrm{SiCl}_{4}\right)$ and either methane $\left(\mathrm{CH}_{4}\right)$ or toluene $\left(\mathrm{C}_{7} \mathrm{H}_{8}\right)$. The liquid $\mathrm{SiCl}_{4}$ and $\mathrm{C}_{7} \mathrm{H}_{8}$ were stored in stainless steel bubblers placed in a water bath whose temperature was maintained at $24.3^{\circ} \mathrm{C}$ by a thermostat. The corresponding vapor pressure of $\mathrm{SiCl}_{4}$ and $\mathrm{C}_{7} \mathrm{H}_{8}$ at this temperature is $30.7 \mathrm{kPa}$ and $3.6 \mathrm{kPa}$, respectively. Hydrogen, purified by Ag-Pd alloy membranes, was utilized both as a diluting and carrier gas, directing the precursors from the bubblers to the reaction chamber. During the deposition, the substrate was situated in an inductively heated SiC-coated graphite susceptor. The temperature control within the reactor was realized by an optical pyrometer which measures the temperature through a view port. A throttle valve located between the chamber and the process pump regulated the pressure by adjusting its degree of opening. All 3C-SiC coatings in this study were prepared at a pressure of $10 \mathrm{kPa}$ with a $p_{\mathrm{C}} / p_{\mathrm{Si}}=1$ and a $p_{\mathrm{H} 2} / p_{\mathrm{Si}}=23$ in the gas phase, at temperatures between $1100{ }^{\circ} \mathrm{C}$ and $1350{ }^{\circ} \mathrm{C}$ for the $\mathrm{C}_{7} \mathrm{H}_{8}$ process and between $1100{ }^{\circ} \mathrm{C}$ and $1400{ }^{\circ} \mathrm{C}$ for the $\mathrm{CH}_{4}$ process.

Characterization. The 3C-SiC coated graphite plates were broken into 4 equal-sized pieces along the gas flow direction to probe the film deposition. The characterizations, i.e. X-ray diffraction (XRD), scanning electron microscopy (SEM) and Raman measurement, have been carried out mainly on the third piece from the inlet of the susceptor. The structure and phase of as-deposited samples was examined by XRD (PANalytical X'Pert PRO Powder X-ray Diffractometer) operating at a voltage of $45 \mathrm{kV}$ and a current of $40 \mathrm{~mA}$. The characteristic Cu$K \alpha$ radiation with a wavelength of $1.54 \AA$ was used to perform the $\theta / 2 \theta$-scan between $20^{\circ}$ and $140^{\circ}$ in a Bragg-Brentano configuration with a divergence and an anti-scatter slit of $0.5^{\circ}$. A Ni filter was placed before the $X^{\prime}$ Celerator detector running in scanning line mode to remove $\mathrm{Cu}-\mathrm{K} \beta$ line. The resultant diffraction patterns were compared to the Powder Diffraction File (PDF) cards and the reflection peaks corresponding to certain lattice planes were assigned. The PDF cards that were referenced for $3 \mathrm{C}-\mathrm{SiC}$ and graphite in this work are \#00-029-1129 and \#00-056-0159, respectively. The preferred growth orientation of the 3CSiC coatings was quantified by the texture coefficient (TC) ${ }^{9}$ defined as follows: 


$$
T C_{(h k l)}=\frac{I_{m(h k l)} / I_{0(h k l)}}{\left(\frac{1}{n}\right) \sum\left[I_{m(h k l)} / I_{0(h k l)}\right]}
$$

where $(h k l)$ is the growth plane considered, $I_{m}$ the normalized measured intensity (with the background intensity subtracted), Io the intensity of a randomly oriented polycrystalline sample (taken from the PDF card) and $n$ the number of planes that are considered. Here, plane (111), (200), (220), (311), (222) and (331) were used for the TC calculation; therefore, $n$ was equal to 6 . The surface morphology and cross-section of the samples were probed by a field emission SEM (ZEISS LEO1550) using an acceleration voltage of $3 \mathrm{kV}$ at a working distance around $5 \mathrm{~mm}$. The existence of pyrolytic carbon in the coatings were investigated by a Raman spectrometer where Ar laser with a wavelength of $532 \mathrm{~nm}$ and a power of $10 \mathrm{~mW}$ was employed to excite the chemical bonds.

Computational methods. The adsorption behaviors of $\mathrm{C}_{6} \mathrm{H}_{6}$ and $\mathrm{CH}_{3}$ molecules on $3 \mathrm{C}-\mathrm{SiC}$ (111) and (110) planes were studied by quantum chemical calculation via the software Gaussian $16^{20}$. The (111) and (110) surfaces are modeled using $\mathrm{Si}_{15} \mathrm{C}_{15}$ and $\mathrm{Si}_{16} \mathrm{C}_{16}$ clusters, respectively, both containing 4 atomic planes. To preserve the bulk structure of $\mathrm{SiC}$, the lateral and bottom side of the clusters are saturated with hydrogen atoms. As for the top surface, the (111) plane is terminated with Si atoms without $\mathrm{H}$-saturation, while on the (110) plane only $\mathrm{C}$ atoms are saturated with hydrogen. The geometries of these clusters are optimized by calculations based on density functional theory (DFT) using B3LYP functionals ${ }^{21,22}$ with the 6$31 \mathrm{G}(d, p)$ basis set and the empirical dispersion corrections D3 proposed by Grimme et al. ${ }^{23}$ The spin configuration giving the lowest energy and the least distorted structure were used for each cluster. The adsorption energy, $E_{\text {ads, }}$ is calculated as follows:

$$
E_{\text {ads }}=E_{\text {optimized geometry }}-\left(E_{\text {cluster }}+E_{\text {molecule }}\right),
$$

where $E_{\text {cluster }}$ and $E_{\text {molecue }}$ is the energy of bare surfaces and of molecules, e.g. $\mathrm{C}_{6} \mathrm{H}_{6}$ or $\mathrm{CH}_{3}$, in the gas phase, respectively, while Eoptimized geometry is the energy of the optimized structure including both adsorbate and adsorbent. 


\section{Results and Discussion}

The use of $\mathrm{C}_{7} \mathrm{H}_{8}$ as the carbon source resulted in distinct surface morphologies and crosssections as shown in Figure 1 and Figure 2, respectively. At a deposition temperature equal to or lower than $1250{ }^{\circ} \mathrm{C}$, the growth is columnar, and the sample surface is dominated with the crystals resembling the top of hexagonal pyramids. It can also be noticed that the crystal size first increases when temperature rises from $1100{ }^{\circ} \mathrm{C}$ to $1200^{\circ} \mathrm{C}$ and slightly decreases at $1250{ }^{\circ} \mathrm{C}$. The 6-fold symmetric pyramids was assumed to be formed by a pair of twin triangular pyramids joining each other ${ }^{12}$ and is a typical morphology of coatings with $<111>$-oriented face-centered cubic (FCC) crystal structure ${ }^{24}$, whereas the pyramids with 4-fold symmetry was reported to be FCC crystals with $<110>$ orientation ${ }^{24}$. The dense and dark striations seen in either the surface morphologies (Figure 1) or the cross-sections (Figure 2) of the samples prepared at $\mathrm{T} \leq 1250^{\circ} \mathrm{C}$ has previously been shown to be twins parallel to the (111) planes ${ }^{13}$, implying that these samples are highly $<111>$-oriented. When the temperature is further increased above $1300^{\circ} \mathrm{C}$, the surface turns into loose fibers and the coating becomes porous, suggesting a different deposition chemistry.

Figure $3(\mathrm{a})$ presents the $\theta-2 \theta$ scan X-ray diffractograms of the coatings prepared with $\mathrm{SiCl}_{4}$ and $\mathrm{C}_{7} \mathrm{H}_{8}$ at various temperatures. $3 \mathrm{C}$ - $\mathrm{SiC}$ is the major crystalline phase detected in most of the samples. At $\mathrm{T} \leq 1250^{\circ} \mathrm{C}$, the samples are highly-<111> oriented because the diffractions from 3C-SiC (111), (222) and (333) planes, corresponding to $2 \theta$ of $35.6^{\circ}, 75.5^{\circ}$ and $133.4^{\circ}$, are almost the only peaks observed. At $\mathrm{T} \geq 1300{ }^{\circ} \mathrm{C}$, the intense peak from $3 \mathrm{C}$-SiC (220) plane at $2 \theta=60.0^{\circ}$ indicates that the coatings are more $<110>$-oriented. At $\mathrm{T}=1350{ }^{\circ} \mathrm{C}$, a rather weak graphite peak at $2 \theta=77.5^{\circ}$ from the substrate is also observed. 


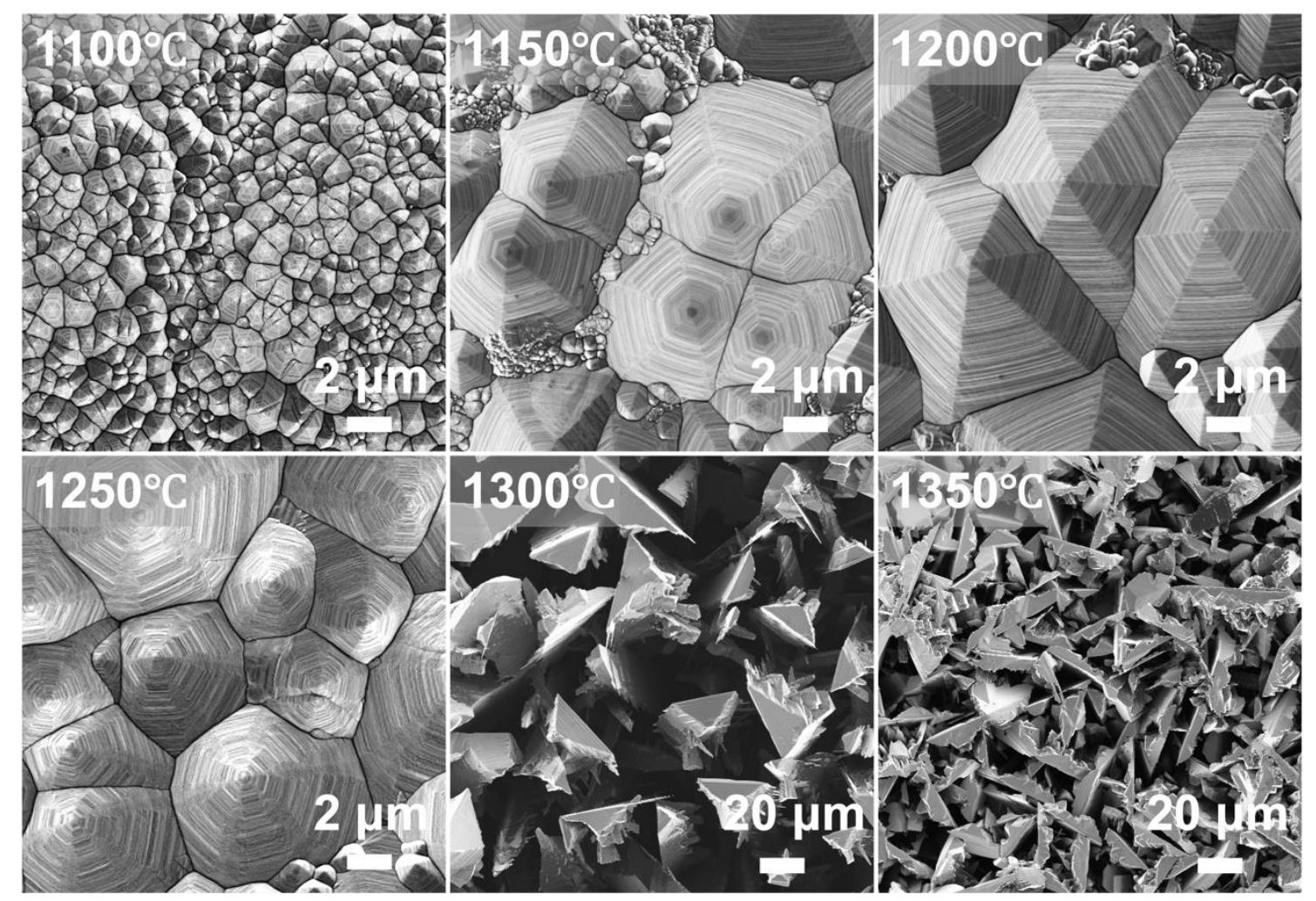

Figure 1. Surface morphologies of $3 \mathrm{C}$-SiC coatings deposited with $\mathrm{SiCl}_{4}$ and $\mathrm{C}_{7} \mathrm{H}_{8}$ at various temperatures

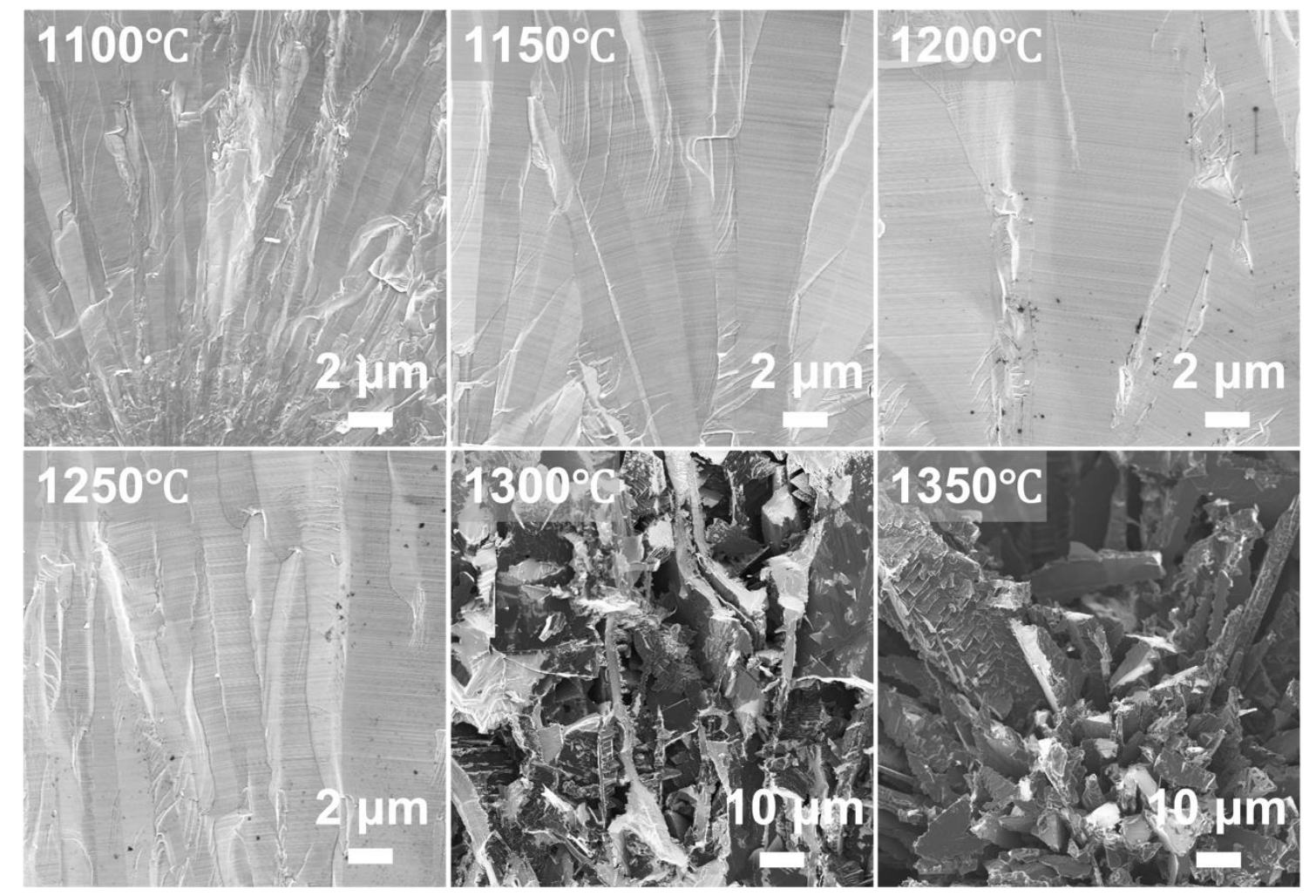

Figure 2. Cross sections of $3 \mathrm{C}-\mathrm{SiC}$ coatings deposited with $\mathrm{SiCl}_{4}$ and $\mathrm{C}_{7} \mathrm{H}_{8}$ at various temperatures 
(a)

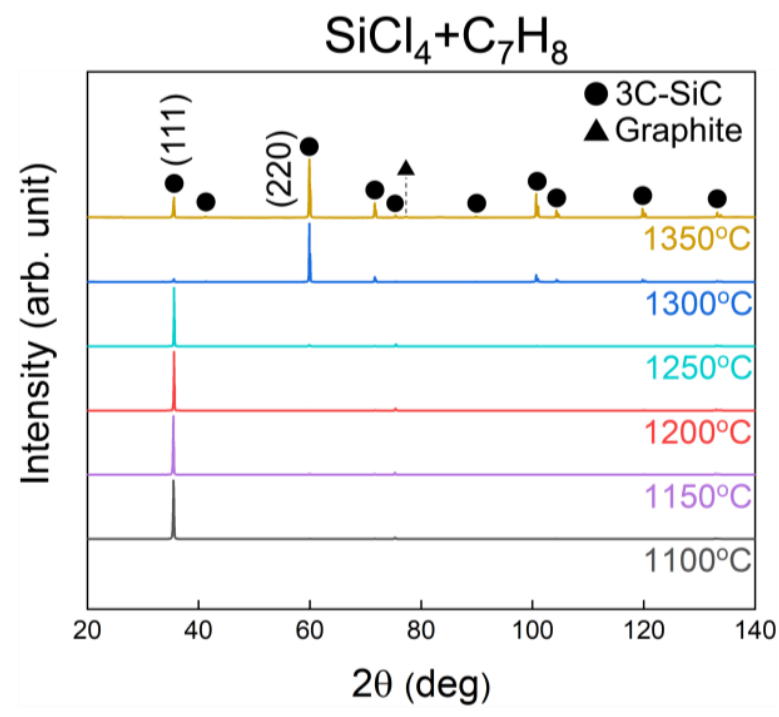

(c)

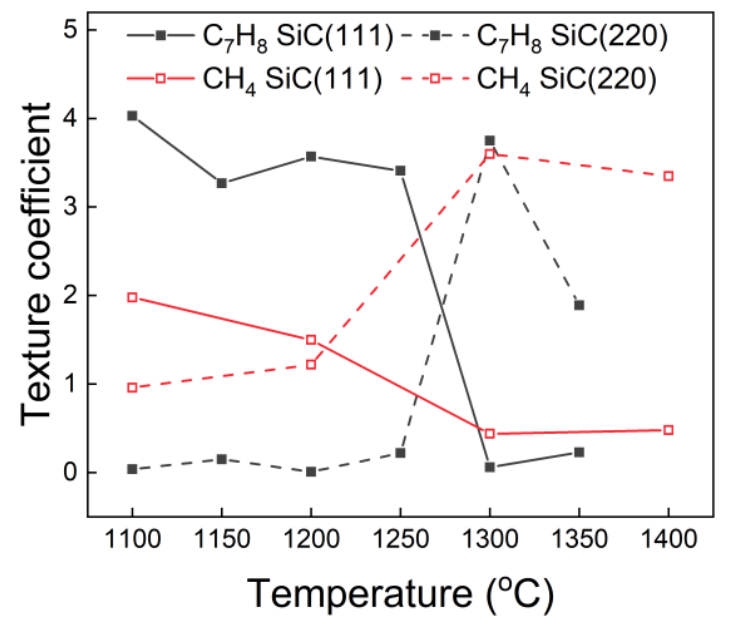

(b)

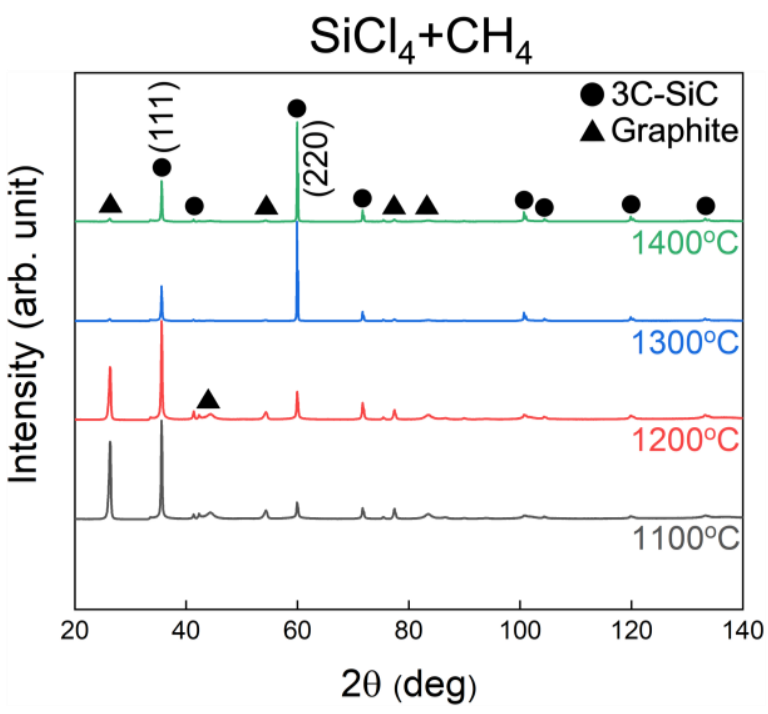

Figure 3. (a) and (b) are the $\theta-2 \theta$ scan diffractograms of 3C-SiC coatings deposited at various temperatures using (a) $\mathrm{C}_{7} \mathrm{H}_{8}$ and (b) $\mathrm{CH}_{4}$, respectively, as carbon-precursor. (c) displays the variation of (111) and (220) texture coefficients with deposition temperatures

Under similar conditions, $\mathrm{CH}_{4}$ has also been utilized for the growth of $3 \mathrm{C}$-SiC coatings. The surface morphology, cross-sections and diffractograms of the deposited coatings are displayed in Figure 4, Figure 5 and Figure $3(\mathrm{~b})$, respectively. At $\mathrm{T} \leq 1200{ }^{\circ} \mathrm{C}$, the surface resembles cauliflowers with small, non-facetted SiC crystallites, whereas at $\mathrm{T}>1200{ }^{\circ} \mathrm{C}$ faceted crystals which increase in size with increasing deposition temperature are formed. A growth mode transition from fine crystallite to columnar with increasing temperature can be observed in the cross-sectional images shown in Figure 5. In contrast to the $\mathrm{C}_{7} \mathrm{H}_{8}$ process where a shift of growth orientation from $<111>$ to $<110\rangle$ is seen with higher temperatures, the diffractograms for the $3 \mathrm{C}$-SiC coatings prepared in the $\mathrm{CH}_{4}$ process show a change from randomly oriented to $<110>$-oriented growth between $1200{ }^{\circ} \mathrm{C}$ and $1300^{\circ} \mathrm{C}$. 
In Figure 3(c) the quantified growth orientation, i.e., the texture coefficient (TC), of 3C-SiC coatings deposited with $\mathrm{C}_{7} \mathrm{H}_{8}$ and $\mathrm{CH}_{4}$ is plotted versus the deposition temperature. (111) and (110) planes of 3C-SiC are chosen for comparison because they are the first and second strongest reflections in the diffractogram of randomly oriented polycrystalline 3C-SiC powder. For both $\mathrm{C}_{7} \mathrm{H}_{8}$ and $\mathrm{CH}_{4}$ processes, a transition of growth orientation can be observed. At higher temperatures $\left(\mathrm{C}_{7} \mathrm{H}_{8}: \mathrm{T} \geq 1300{ }^{\circ} \mathrm{C}, \mathrm{CH}_{4}: \mathrm{T}>1200{ }^{\circ} \mathrm{C}\right)$, the $3 \mathrm{C}$-SiC coatings from both processes are highly $<110>$-oriented. At lower temperatures $\left(\mathrm{C}_{7} \mathrm{H}_{8}: \mathrm{T} \leq 1250{ }^{\circ} \mathrm{C}, \mathrm{CH}_{4}: \mathrm{T}<\right.$ $1200{ }^{\circ} \mathrm{C}$ ), 3C-SiC coatings deposited with $\mathrm{CH}_{4}$ exhibit no strongly preferred growth orientation, whereas the ones prepared with $\mathrm{C}_{7} \mathrm{H}_{8}$ are highly $<111>$-oriented. These observations are in accord with the change in surface morphology seen in the SEM images. Because the deposition conditions in both sets of experiments were similar except for the used hydrocarbon, it is inferred that the difference in growth orientation at low temperature is caused by the choice of hydrocarbon.
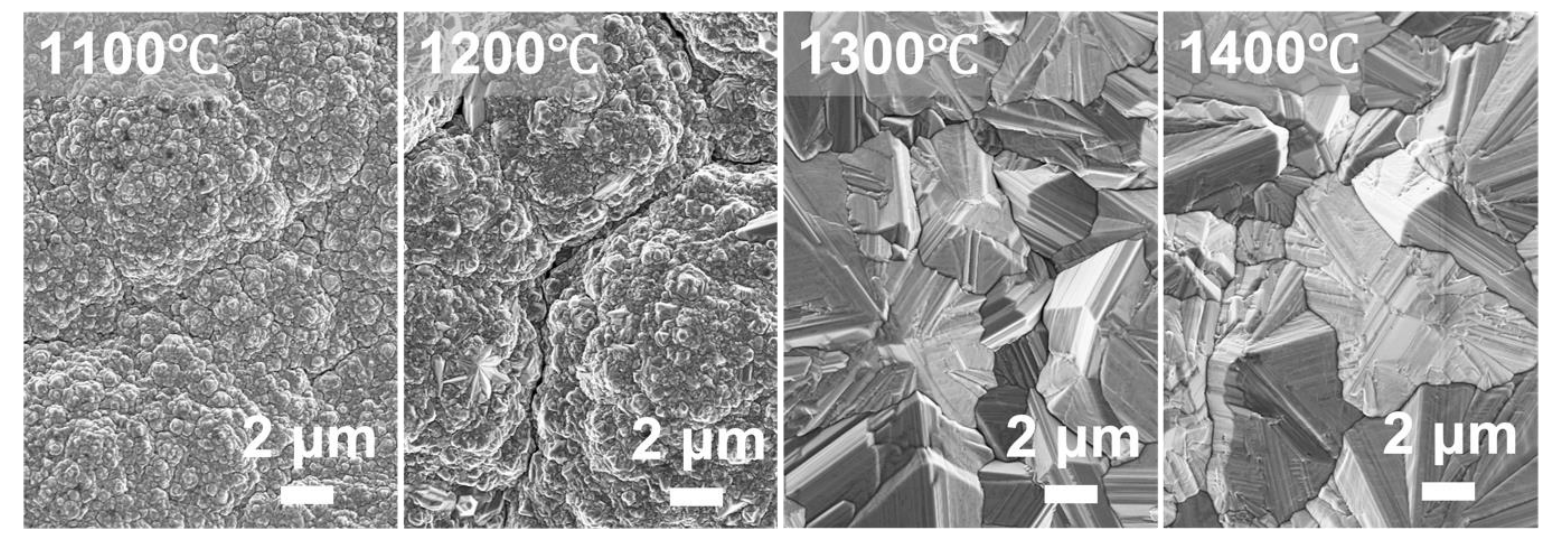

Figure 4. Surface morphologies of $3 \mathrm{C}$-SiC coatings deposited with $\mathrm{SiCl}_{4}$ and $\mathrm{CH}_{4}$ at various temperatures 


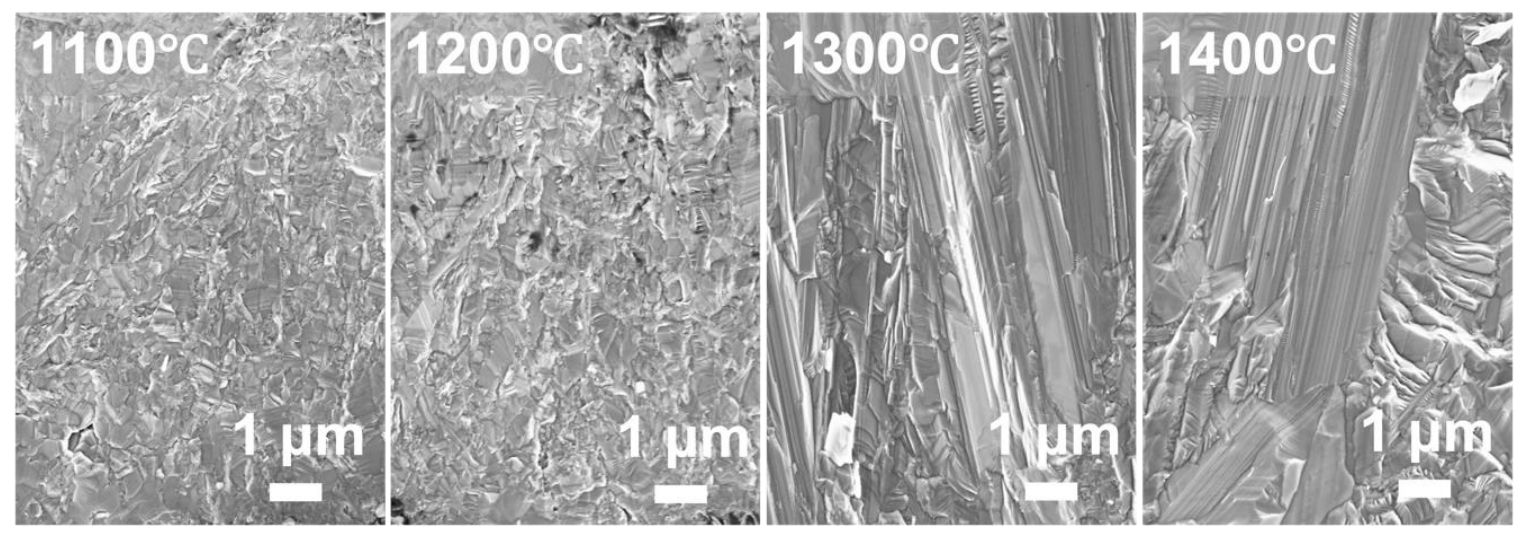

Figure 5. Cross sections of $3 \mathrm{C}$-SiC coatings deposited with $\mathrm{SiCl}_{4}$ and $\mathrm{CH}_{4}$ at various temperatures

In order to investigate whether the use of aromatic hydrocarbons would result in the formation of excess carbon in the films, the Raman measurements have been performed on the $3 \mathrm{C}$-SiC coatings deposited either with $\mathrm{CH}_{4}$ or $\mathrm{C}_{7} \mathrm{H}_{8}$ as shown in Figure 6 . In the $\mathrm{CH}_{4}$ process, the Raman spectra of deposited 3C-SiC coatings shows a Raman shift deviation of $\pm 1 \mathrm{~cm}^{-1}$ in both $1^{\text {st }}$ order $3 \mathrm{C}$-SiC transverse optical (TO) and longitudinal optical (LO) mode. The Raman shifts for $1^{\text {st }}$ order TO and MO modes of bulk $3 C$-SiC are reported to be $796 \mathrm{~cm}^{-1}$ and $972 \mathrm{~cm}^{-}$ ${ }^{1}$, respectively ${ }^{25}$. On the other hand, an even higher deviation of Raman shift for $1^{\text {st }}$ order TO and $\mathrm{MO}$ modes is observed in the $3 \mathrm{C}$-SiC coatings prepared with $\mathrm{C}_{7} \mathrm{H}_{8}$ with the corresponding TO at $794 \pm 2 \mathrm{~cm}^{-1}$ and LO at $967 \pm 2 \mathrm{~cm}^{-1}$. The $2^{\text {nd }}$ order TO and LO modes of $3 C-\mathrm{SiC}^{26}$ at 1520 $\mathrm{cm}^{-1}$ and $1710 \mathrm{~cm}^{-1}$, respectively, are also detected in both processes. Moreover, at lower temperatures $\left(\mathrm{C}_{7} \mathrm{H}_{8}: \mathrm{T}<1200{ }^{\circ} \mathrm{C}, \mathrm{CH}_{4}: \mathrm{T} \leq 1200{ }^{\circ} \mathrm{C}\right)$, broadened transverse acoustic (TA) and longitudinal acoustic (LA) modes of 3C-SiC, which are normally located between 150 and 600 $\mathrm{cm}^{-1}$, are observed, indicating the existence of smaller SiC crystallites ${ }^{27-29}$. However, at $\mathrm{T} \geq$ $1300{ }^{\circ} \mathrm{C}$, the characteristic Raman modes for carbon phases, e.g. D-band at $1350 \mathrm{~cm}^{-1}$, G-band at $1580 \mathrm{~cm}^{-1}$ and $2 \mathrm{D}$ band at $2701 \mathrm{~cm}^{-127}$, are observed in the $3 C$-SiC samples prepared with $\mathrm{C}_{7} \mathrm{H}_{8}$, indicating the co-deposition of pyrolytic carbon. It is noteworthy that the appearance of these Raman peaks is observed at the same temperature as the shift from $<111>$ to $\langle 110\rangle$ oriented growth. This could be caused by the breakdown of the toluene molecules forming highly reactive intermediates at such high temperatures. It could also be possible that the $\mathrm{Si}$ precursor is depleted faster than the $\mathrm{C}$ precursor, leaving excess carbon species in the coating. Either way, the presence of pyrolytic carbon indicates a change in the growth chemistry, which could be the cause of the change in crystalline orientation and morphology as seen in 
SEM and XRD. Interestingly, no signs of pyrolytic carbon can be found in the coatings grown from $\mathrm{CH}_{4}$, even at high temperatures. A possible explanation is the different decomposition products of the hydrocarbons. Toluene will decompose into larger hydrocarbons that may more easily form condensed deposits, while $\mathrm{CH}_{4}$ will only break down into even smaller radicals, which are less prone to form condensed pyrolytic carbon deposits.

(a)

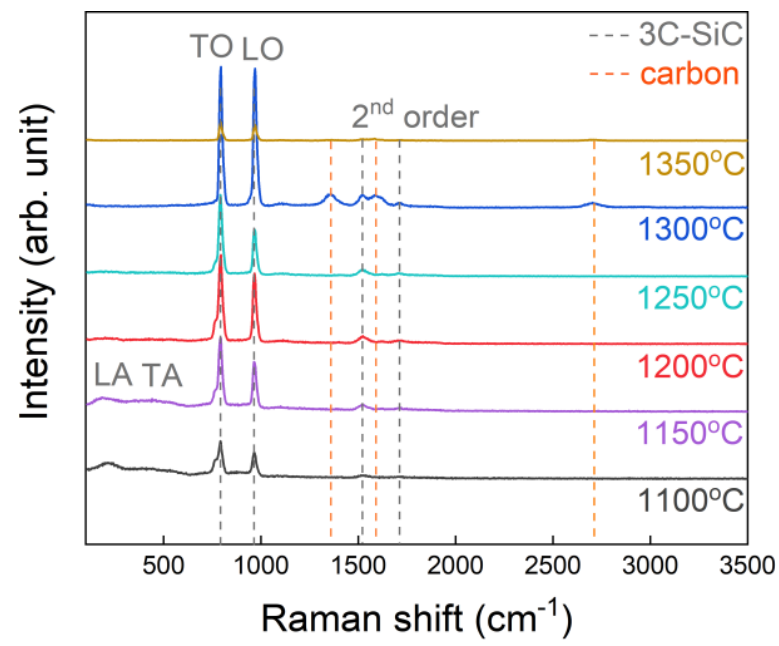

(b)

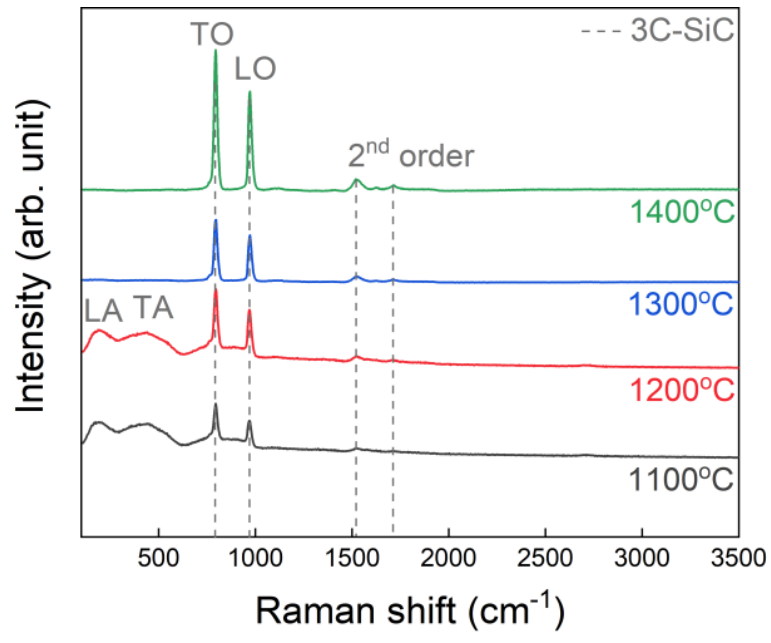

Figure 6. Raman spectra of 3C-SiC deposited at various temperatures using $\mathrm{SiCl}_{4}$ as the $\mathrm{Si}$ precursor and (a) $\mathrm{C}_{7} \mathrm{H}_{8}$ and (b) $\mathrm{CH}_{4}$ as carbon precursor.

The different growth regimes in the $\mathrm{C}_{7} \mathrm{H}_{8}$ process can also be observed in the Arrhenius plot displayed in Figure 7. From the data, there seems to be three growth regimes in the $\mathrm{C}_{7} \mathrm{H}_{8}$ process. For $\mathrm{T} \leq 1250^{\circ} \mathrm{C}$, the Arrhenius plot suggests that the growth is kinetically limited with an activation energy of $103 \mathrm{~kJ} / \mathrm{mol}$. At $1250{ }^{\circ} \mathrm{C}<\mathrm{T}<1300{ }^{\circ} \mathrm{C}$, the kinetics-controlled growth seems to retain but with a much higher activation energy. In this temperature range, the preferred growth orientation of $3 \mathrm{C}-\mathrm{SiC}$ deposited with toluene switches from $<111>$ to $<110>$ direction and free carbon also starts to be incorporated into the films. The change of the slope in the Arrhenius plot and in the preferred growth orientation can be interpreted as an indication of change in the deposition chemistry. It should be noted that a change in deposition chemistry can also result in a change in reaction order, meaning that, e.g. the rate constant in the Arrhenius equation is not the same over the entire investigated temperature range in Figure. 7 . When the temperature continues to rise above $1300{ }^{\circ} \mathrm{C}$, the deposition again alters its character, and the films grow in the form of more flake-like crystals (Figure 1). 
This alteration is represented by a plateau in Figure 7 , suggesting that at $\mathrm{T} \geq 1300{ }^{\circ} \mathrm{C}$ the deposition chemistry enters the mass-transport limited regime with an apparent activation energy of $5 \mathrm{~kJ} / \mathrm{mol}$. On the other hand, the $3 \mathrm{C}$-SiC growth in the $\mathrm{CH}_{4}$ process appears to be kinetics limited with an activation energy of $85 \mathrm{~kJ} / \mathrm{mol}$ between $1100{ }^{\circ} \mathrm{C}$ and $1400{ }^{\circ} \mathrm{C}$ and the preferred growth orientation changes from randomly oriented to highly $<110>$ at $\mathrm{T}>1200^{\circ} \mathrm{C}$.

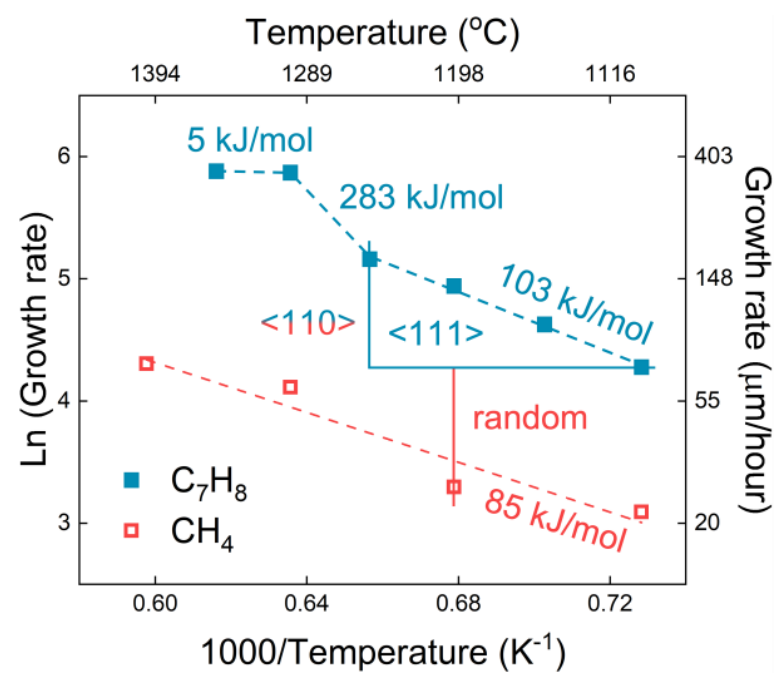

Figure 7. Arrhenius plot for $\mathrm{SiCl}_{4}$ based 3CSiC coatings using either $\mathrm{CH}_{4}$ or $\mathrm{C}_{7} \mathrm{H}_{8}$ as carbon precursor. The data points from both processes are fitted with dashed lines.

To further understand the deposition chemistry, the adsorption behaviors of $\mathrm{C}_{6} \mathrm{H}_{6}$ and $\mathrm{CH}_{3}$ on the 3C-SiC (111) and (110) planes are studied by DFT calculations. A toluene molecule consists of a benzene ring $\left(\mathrm{C}_{6} \mathrm{H}_{6}\right)$ with one of its $\mathrm{H}$ atoms replaced by a methyl group $\left(\mathrm{CH}_{3}\right)$, whereas a methane molecule is composed of four equivalent $\mathrm{C}-\mathrm{H}$ bonds forming a tetrahedron. In an environment with large excess of hydrogen and at elevated temperatures, toluene was reported to undergo two possible decomposition pathways ${ }^{30,31}$ :

(1) $\mathrm{H}_{2}+\mathrm{C}_{6} \mathrm{H}_{5} \mathrm{CH}_{3} \rightarrow \mathrm{C}_{6} \mathrm{H}_{6}+\mathrm{CH}_{4}$

(2) $\mathrm{H}+\mathrm{C}_{6} \mathrm{H}_{5} \mathrm{CH}_{3} \rightarrow \mathrm{C}_{6} \mathrm{H}_{6}+\mathrm{CH}_{3}$

$\mathrm{CH}_{4}$ does not directly contribute towards the $\mathrm{SiC}$ growth ${ }^{32}$, but only via the decomposition into $\mathrm{CH}_{3}$. The active carbon species for the adsorption studies are thus considered to be $\mathrm{C}_{6} \mathrm{H}_{6}$ and $\mathrm{CH}_{3}$ species. Figure 8 presents the calculation results for the adsorption of the abovementioned two molecules on $3 \mathrm{C}$-SiC (111) and (110) planes. It can be noticed that $\mathrm{CH}_{3}$ is easily adsorbed on both planes and the adsorption energy on (111) and (110) is calculated to be $-376 \mathrm{~kJ} / \mathrm{mol}$ and $-368 \mathrm{~kJ} / \mathrm{mol}$, respectively. Moreover, the distance between the $\mathrm{C}$ atom 
from the $\mathrm{CH}_{3}$ and the surface $\mathrm{Si}$ atom was reduced from the initial $2 \AA$ position to $1.89 \AA$ [(111) plane] and $1.90 \AA$ [(110) plane] after adsorption, which is comparable to the $\mathrm{C}-\mathrm{H}$ bond length in bulk $3 \mathrm{C}$-SiC. The result suggests that the $\mathrm{CH}_{3}$ does not show a strong preference towards the (111) or (110) plane, since the adsorption energies of $\mathrm{CH}_{3}$ on both planes are very close to each other. The $\mathrm{C}_{6} \mathrm{H}_{6}$ molecule is also active towards the (111) plane, exhibiting an adsorption energy of $-278 \mathrm{~kJ} / \mathrm{mol}$. Upon adsorption, the $\mathrm{C}_{6} \mathrm{H}_{6}$ molecule loses its planar symmetry: three $C$ atoms of the molecule move away from the (111) surface, and the other three move down towards the (111) surface. The distance between the three $C$ atoms closest to the surface and the surface $\mathrm{Si}$ atoms are decreased to $1.95 \pm 0.01 \AA$. However, the $\mathrm{C}_{6} \mathrm{H}_{6}$ molecule seems to be rather inactive towards (110) plane, the distance between which after calculation increased from $2 \AA$ to $3.54 \AA$ corresponding to an adsorption energy of $-46 \mathrm{~kJ} / \mathrm{mol}$. Judging from the adsorption energy and the distance between adsorbate and surface, the $\mathrm{C}_{6} \mathrm{H}_{6}$ molecule is considered physiosorbed on the (110) plane, whereas the adsorption of $\mathrm{C}_{6} \mathrm{H}_{6}$ on (111) as well as that of $\mathrm{CH}_{3}$ on both (111) and (110) can be described as chemisorption which would lead to the formation of chemical bonding. 


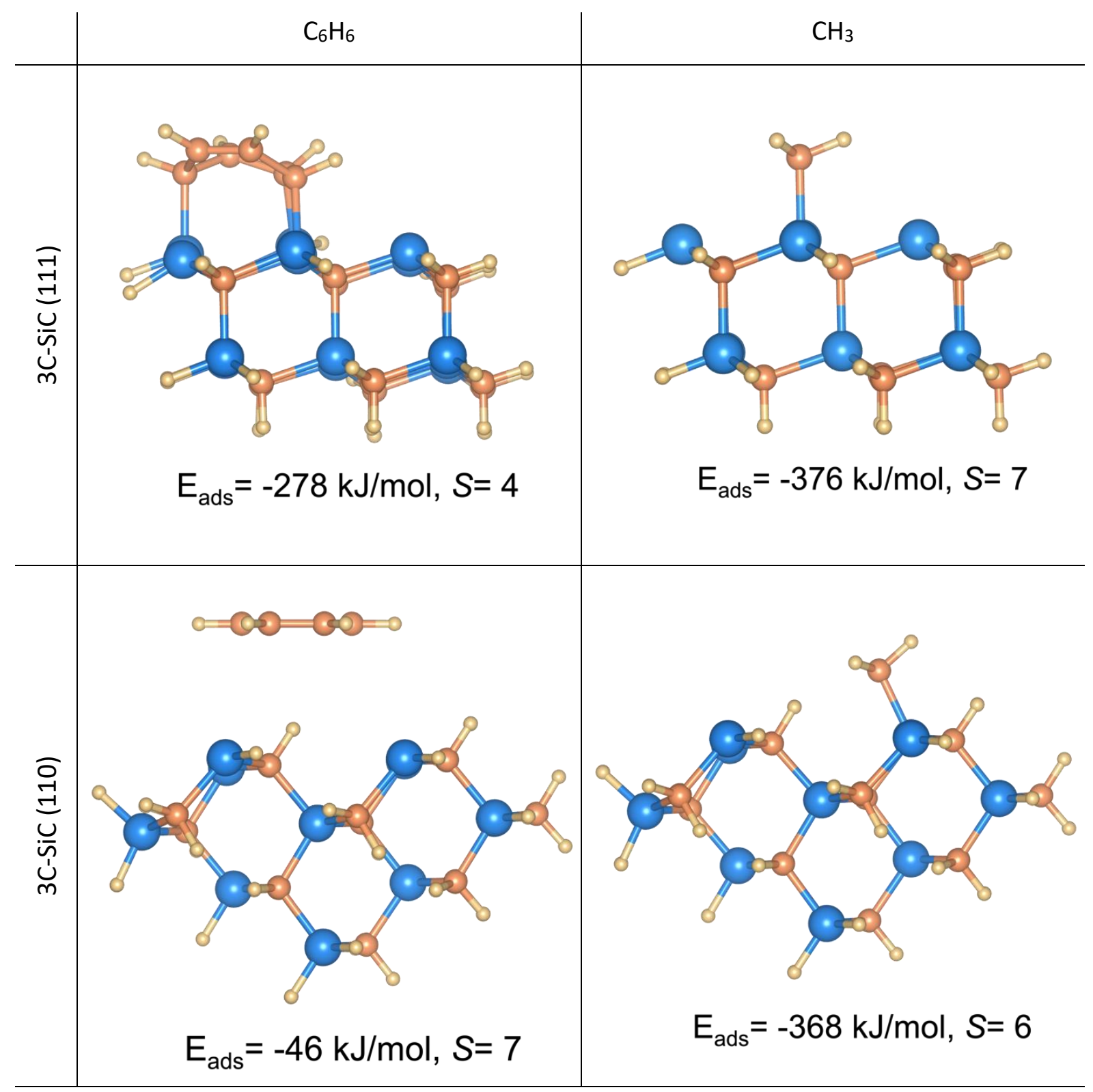

Figure 8. Computational results of the adsorption of $\mathrm{C}_{6} \mathrm{H}_{6}$ and $\mathrm{CH}_{3}$ on $3 \mathrm{C}-\mathrm{SiC}(111)$ and (110) planes and their corresponding adsorption energies, $E_{\text {ads. }} S$ denotes the spin configuration that yielded the lowest energy and the least distorted structure after calculation

The SiC crystals in the films are expected to grow along the atomic direction whose corresponding atomic plane has the lowest surface energy. According to Kikuchi et al., the surface energy of the first three low index 3C-SiC planes, namely, (100), (111) and (110), is 6.8 $\mathrm{J} / \mathrm{m}^{2}, 4.2 \mathrm{~J} / \mathrm{m}^{2}$ and $3.4 \mathrm{~J} / \mathrm{m}^{2}$, respectively ${ }^{6}$. This implies that in the conventional 3C-SiC CVD most of the coatings would grow preferentially along $<110>$ direction. When we use $\mathrm{CH}_{4}$ at $1100-1400{ }^{\circ} \mathrm{C}$ we observe a random or $<110>$-preferred growth direction. By using $\mathrm{C}_{7} \mathrm{H}_{8}$ as 
carbon precursor instead, it was possible to deposit highly $<111>$-oriented $3 \mathrm{C}$-SiC coatings at $\mathrm{T} \leq 1250{ }^{\circ} \mathrm{C}$. This change of preferred growth orientation with aromatic hydrocarbons was previously observed for the CVD growth of TiC hard coatings. ${ }^{17}$ For $\mathrm{TiC}$, this was suggested to be due to the stronger adsorption of $\mathrm{C}_{6} \mathrm{H}_{6}$ on the (111) surface compared to the (100) surface, overcoming the lower surface energy of the (100) surface. ${ }^{19}$ Based on the reported CVD chemistry for toluene ${ }^{30,31}$, the active carbon-containing growth species in the $\mathrm{C}_{7} \mathrm{H}_{8}$ process are assumed to be $\mathrm{C}_{6} \mathrm{H}_{6}$ and $\mathrm{CH}_{3}$, whereas in the $\mathrm{CH}_{4}$ process $\mathrm{CH}_{3}$ is supposed to be the active species. ${ }^{33}$ As described above, the computational results showed that $\mathrm{CH}_{3}$ was chemisorbed on both 3C-SiC (111) and (110) planes, and $\mathrm{C}_{6} \mathrm{H}_{6}$ was chemisorbed on the (111) plane but physiosorbed on the (110) plane. The slight difference in the adsorption energies of $\mathrm{CH}_{3}$ on both (111) and (110) explains the almost randomly oriented $\mathrm{SiC}$ growth in the $\mathrm{CH}_{4}$ process. On the other hand, the highly- $<111>$ oriented $3 \mathrm{C}-\mathrm{SiC}$ coatings prepared using $\mathrm{C}_{7} \mathrm{H}_{8}$ can be assumed to result from the significant adsorption energy difference of $\mathrm{C}_{6} \mathrm{H}_{6}$ on (111) and (110) planes. The energy decrease resulting from the adsorption of $\mathrm{C}_{6} \mathrm{H}_{6}$ on the (111) plane is 6 times larger than that on (110). At higher temperatures, toluene is expected to decompose into various hydrocarbons ${ }^{34}$, and therefore the growth of $3 \mathrm{C}-\mathrm{SiC}$ is no longer directed towards the $<111>$ direction. Without the directing effect of the aromatic hydrocarbon, the growth happens mainly on the (110) planes having the lowest surface energy, which is similar to the case in the $\mathrm{CH}_{4}$ process.

\section{Conclusion}

In this work, we were able to control the preferred growth orientation of 3C-SiC by using either methane $\left(\mathrm{CH}_{4}\right)$ or toluene $\left(\mathrm{C}_{7} \mathrm{H}_{8}\right)$ as the carbon precursor in a SiCl 4 -based SiC CVD. At T $\leq 1250{ }^{\circ} \mathrm{C}$ and $p=10 \mathrm{kPa}$, the resulting $3 \mathrm{C}$-SiC coatings were highly $<111>$-oriented in the $\mathrm{C}_{7} \mathrm{H}_{8}$ process, whereas they were almost randomly oriented in the $\mathrm{CH}_{4}$ process. At $\mathrm{T}>1250{ }^{\circ} \mathrm{C}$ both processes resulted in highly $<110>$-oriented $3 \mathrm{C}$-SiC coatings. By considering $\mathrm{C}_{6} \mathrm{H}_{6}$ and $\mathrm{CH}_{3}$ the main active carbon-containing film forming species, their adsorption behaviors on 3C-SiC (111) and (110) planes were shown via quantum chemical calculation to be significantly different: $\mathrm{C}_{6} \mathrm{H}_{6}$ was chemisorbed on the (111) plane, but physiosorbed on the (110) plane, while $\mathrm{CH}_{3}$ was chemisorbed strongly on both planes. These calculation results indicate that the difference in reactivity of the carbon precursor towards the various planes is the reason for 
the different growth orientations. At $\mathrm{T}>1250{ }^{\circ} \mathrm{C}$, the transition to highly $<110>$-oriented growth in both processes can be explained by the fact that $3 \mathrm{C}-\mathrm{SiC}$ would tend to grow along the direction leading to the lowest surface energy, i.e. (110) plane in 3C-SiC. The steering effect of toluene is no longer present at elevated temperatures due to its expected decomposition into smaller, non-aromatic hydrocarbons.

\section{Acknowledgement}

The authors thank SGL CARBON GmbH for the financial support. L. Ojamäe acknowledges support from the Swedish Research Council (VR). Rickard Liljedahl is acknowledged for fruitful discussions and for the support in sample characterizations. 


\section{Reference}

(1) Choy, K. Chemical Vapour Deposition of Coatings. Progress in Materials Science 2003, 48 (2), 57-170. https://doi.org/10.1016/S0079-6425(01)00009-3.

(2) Pedersen, H.; Leone, S.; Kordina, O.; Henry, A.; Nishizawa, S.; Koshka, Y.; Janzén, E. Chloride-Based CVD Growth of Silicon Carbide for Electronic Applications. Chem. Rev. 2012, 112 (4), 2434-2453. https://doi.org/10.1021/cr200257z.

(3) Aylward, G.; Findlay, T. SI Chemical Data, 4th ed.; John Wiely \& Sons, 1999.

(4) Yazdanfar, M.; Danielsson, Ö.; Kordina, O.; Janzén, E.; Pedersen, H. Finding the Optimum Chloride-Based Chemistry for Chemical Vapor Deposition of SiC. ECS J. Solid State Sci. Technol. 2014, 3 (10), P320-P323. https://doi.org/10.1149/2.0111410jss.

(5) Kim, H.-S.; Choi, D.-J. The Reactant Depletion Effect on Chemically Vapor Deposited SiC Films with Pressure and Gas Ambient. Thin Solid Films 1998, 312 (1-2), 195-201. https://doi.org/10.1016/S0040-6090(97)00744-X.

(6) Kikuchi, H.; Kalia, R. K.; Nakano, A.; Vashishta, P.; Branicio, P. S.; Shimojo, F. Brittle Dynamic Fracture of Crystalline Cubic Silicon Carbide (3C-SiC) via Molecular Dynamics Simulation. Journal of Applied Physics 2005, 98 (10), 103524. https://doi.org/10.1063/1.2135896.

(7) Tu, R.; Zheng, D. H.; Cheng, H.; Han, M. X.; Zhang, S.; Goto, T. Preparation of UltraThick $\beta$-SiC Films Using Different Carbon Sources. Materials Research Innovations 2015, 19 (sup10), S10-397-S10-402. https://doi.org/10.1179/1432891715Z.0000000002205.

(8) Tu, R.; Zheng, D.; Sun, Q.; Han, M.; Zhang, S.; Hu, Z.; Goto, T.; Zhang, L. Ultra-Fast Fabrication of $<110>$-Oriented $\beta$-SiC Wafers by Halide CVD. J. Am. Ceram. Soc. 2016, 99 (1), 84-88. https://doi.org/10.1111/jace.13980.

(9) Lin, T. T.; Hon, M. H. The Growth Characteristics of Chemical Vapour-Deposited $\beta$-SiC on a Graphite Substrate by the $\mathrm{SiCl}_{4} / \mathrm{C}_{3} \mathrm{H}_{8} / \mathrm{H}_{2}$ System. Journal of Materials Science 1995, 30 (10), 2675-2681. https://doi.org/10.1007/bf00362151.

(10) Xu, Q.; Zhu, P.; Sun, Q.; Tu, R.; Zhang, S.; Yang, M.; Li, Q.; Shi, J.; Li, H.; Zhang, L.; Goto, T.; Han, M.; Yan, J.; Li, S.; Ohmori, H. Fast Preparation of (111)-Oriented $\beta$-SiC Films without Carbon Formation by Laser Chemical Vapor Deposition from Hexamethyldisilane without H2. J Am Ceram Soc 2018, 101 (4), 1471-1478. https://doi.org/10.1111/jace.15315.

(11) Zhu, P. P.; Tu, R.; Zhang, S.; Han, M. X.; Xu, Q. F.; Sun, Q. Y.; Zhang, L. M.; Goto, T.; Yan, J. S.; Li, S. S. The Effect of Diluent Gases on the Growth of $\beta$-SiC Films by Laser CVD with HMDS. Materials Research Innovations 2015, 19 (sup10), S10-403-S10-407. https://doi.org/10.1179/1432891715Z.0000000002208.

(12) Zhang, S.; Xu, Q.; Sun, Q.; Zhu, P.; Tu, R.; Hu, Z.; Han, M.; Goto, T.; Zhang, L.; Yan, J.; Li, S. Effect of Pressure on Microstructure of <111>-Oriented $\beta$-SiC Films: Research via Electron Backscatter Diffraction. J. Am. Ceram. Soc. 2015, 98 (12), 3713-3718. https://doi.org/10.1111/jace.13823.

(13) Zhang, S.; Xu, Q.; Tu, R.; Goto, T.; Zhang, L. High-Speed Preparation of <111>- and $<110>$-Oriented $\beta$-SiC Films by Laser Chemical Vapor Deposition. J. Am. Ceram. Soc. 2014, 97 (3), 952-958. https://doi.org/10.1111/jace.12706.

(14) Zhang, S.; Xu, Q.; Tu, R.; Goto, T.; Zhang, L. Growth Mechanism and Defects of Oriented $\beta$-SiC Films Deposited by Laser Chemical Vapor Deposition. J. Am. Ceram. Soc. 2015, 98 (1), 236-241. https://doi.org/10.1111/jace.13248. 
(15) Nagai, M.; Shishikura, I.; Omi, S. Molybdenum Carbide Prepared by Chemical Vapor Deposition. Jpn. J. Appl. Phys. 2000, 39 (Part 1, No. 7B), 4528-4531.

https://doi.org/10.1143/JJAP.39.4528.

(16) Zhuravlov, A. Yu.; Hovanskiy, N. A.; Khizhnyak, D. A.; Shirokov, B. M.; Semenov, N. A.; Shijan, A. V.; Strigunovskiy, S. V.; Yevsiukov, A. I.; Shevtsov, A. B.; Nazarenko, E. A.; Pilipenko, N. N. Obtaining Silicon Carbide via Chemical Vapor, Plasma-Chemical and Sublimation Methods. Problems of Atomic Science and Technology 2017.

(17) Leonhardt, A.; Wolf, E. Influence of Different Hydrocarbons on the Structure of CVDand PACVD-TiCx Hard Layers. Materials Science and Engineering: A 1996, 209 (1-2), 389-393. https://doi.org/10.1016/0921-5093(95)10110-1.

(18) López-Romero, S.; Chávez-Ramírez, J. Synthesis of TiC Thin Films by CVD from Toluene and Titanium Tetrachloride with Nickel as Catalyst. Matéria (Rio de Janeiro) 2007, 12 (3), 487-493. https://doi.org/10.1590/s1517-70762007000300009.

(19) Pedersen, H.; Lin, C.-C.; Ojamäe, L. On the Change of Preferential Growth Orientation in Chemical Vapor Deposition of Titanium Carbide by Aromatic Hydrocarbon Precursors. Journal of Vacuum Science \& Technology A: Vacuum, Surfaces, and Films 2013, 31 (2), 021507. https://doi.org/10.1116/1.4792723.

(20) M. J. Frisch, G. W. Trucks, H. B. Schlegel, G. E. Scuseria,; M. A. Robb, J. R. Cheeseman, G. Scalmani, V. Barone,; G. A. Petersson, H. Nakatsuji, X. Li, M. Caricato, A. V. Marenich,; J. Bloino, B. G. Janesko, R. Gomperts, B. Mennucci, H. P. Hratchian,; J. V. Ortiz, A. F. Izmaylov, J. L. Sonnenberg, D. Williams-Young,; F. Ding, F. Lipparini, F. Egidi, J. Goings, B. Peng, A. Petrone,; T. Henderson, D. Ranasinghe, V. G. Zakrzewski, J. Gao, N. Rega,; G. Zheng, W. Liang, M. Hada, M. Ehara, K. Toyota, R. Fukuda,; J. Hasegawa, M. Ishida, T. Nakajima, Y. Honda, O. Kitao, H. Nakai,; T. Vreven, K. Throssell, J. A. Montgomery, Jr., J. E. Peralta,; F. Ogliaro, M. J. Bearpark, J. J. Heyd, E. N. Brothers, K. N. Kudin,; V. N. Staroverov, T. A. Keith, R. Kobayashi, J. Normand,; K. Raghavachari, A. P. Rendell, J. C. Burant, S. S. Iyengar,; J. Tomasi, M. Cossi, J. M. Millam, M. Klene, C. Adamo, R. Cammi,; J. W. Ochterski, R. L. Martin, K. Morokuma, O. Farkas,; J. B. Foresman, and D. J. Fox. Gaussian 16, Revision C.01; Gaussian, Inc.: Wallingford CT, 2019.

(21) Becke, A. D. Density-functional Thermochemistry. III. The Role of Exact Exchange. The Journal of Chemical Physics 1993, 98 (7), 5648-5652. https://doi.org/10.1063/1.464913.

(22) Lee, C.; Yang, W.; Parr, R. G. Development of the Colle-Salvetti Correlation-Energy Formula into a Functional of the Electron Density. Phys. Rev. B 1988, 37 (2), 785-789. https://doi.org/10.1103/PhysRevB.37.785.

(23) Grimme, S.; Antony, J.; Ehrlich, S.; Krieg, H. A Consistent and Accurate Ab Initio Parametrization of Density Functional Dispersion Correction (DFT-D) for the 94 Elements H-Pu. The Journal of Chemical Physics 2010, 132 (15), 154104. https://doi.org/10.1063/1.3382344.

(24) Tu, R.; Zheng, D.; Cheng, H.; Hu, M.; Zhang, S.; Han, M.; Goto, T.; Zhang, L. Effect of $\mathrm{CH} 4 / \mathrm{SiCl} 4$ Ratio on the Composition and Microstructure of $<110>$-Oriented $\beta$-SiC Bulks by Halide CVD. Journal of the European Ceramic Society 2017, 37 (4), 12171223. https://doi.org/10.1016/j.jeurceramsoc.2016.11.015.

(25) Feldman, D. W.; Parker, J. H.; Choyke, W. J.; Patrick, L. Phonon Dispersion Curves by Raman Scattering in SiC, Polytypes 3C,4H,6H,15R, and 21R. Phys. Rev. 1968, 173 (3), 787-793. https://doi.org/10.1103/PhysRev.173.787. 
(26) Feng, Z. C.; Tin, C. C.; Hu, R.; Williams, J. Raman and Rutherford Backscattering Analyses of Cubic SiC Thin Films Grown on Si by Vertical Chemical Vapor Deposition. Thin Solid Films 1995, 266 (1), 1-7. https://doi.org/10.1016/0040-6090(95)06599-7.

(27) Dasgupta, A.; Klein, S.; Houben, L.; Carius, R.; Finger, F.; Luysberg, M. Microstructure of Highly Crystalline Silicon Carbide Thin Films Grown by HWCVD Technique. Thin Solid Films 2008, 516 (5), 618-621. https://doi.org/10.1016/j.tsf.2007.06.055.

(28) Dasgupta, A.; Huang, Y.; Houben, L.; Klein, S.; Finger, F.; Carius, R.; Luysberg, M. Effect of Filament and Substrate Temperatures on the Structural and Electrical Properties of SiC Thin Films Grown by the HWCVD Technique. Thin Solid Films 2008, 516 (5), 622625. https://doi.org/10.1016/j.tsf.2007.06.077.

(29) Ward, Y.; Young, R. J.; Shatwell, R. A. A Microstructural Study of Silicon Carbide Fibres through the Use of Raman Microscopy. 2001, 12.

(30) Amano, A.; Tominaga, H.; Tokuhisa, H. Mechanism of Thermal Hydrogenolysis of Toluene. Bull. Japan Petrol. Inst. 1965, 7, 59-63. https://doi.org/10.1627/jpi1959.7.59.

(31) Amano, A.; Horie, O.; Hanh, N. H. Effect of Thermal Activation on the Reaction of Toluene with Hydrogen Atoms. Int. J. Chem. Kinet. 1976, 8 (3), 321-339. https://doi.org/10.1002/kin.550080302.

(32) Sukkaew, P.; Danielsson, Ö.; Kordina, O.; Janzén, E.; Ojamäe, L. Ab Initio Study of Growth Mechanism of $4 \mathrm{H}-\mathrm{SiC}$ : Adsorption and Surface Reaction of $\mathrm{C}_{2} \mathrm{H}_{2}, \mathrm{C}_{2} \mathrm{H}_{4}, \mathrm{CH}_{4}$, and $\mathrm{CH}_{3}$. J. Phys. Chem. C 2017, 121 (2), 1249-1256. https://doi.org/10.1021/acs.jpcc.6b11085.

(33) Stenberg, P.; Danielsson, Ö.; Erdtman, E.; Sukkaew, P.; Ojamäe, L.; Janzén, E.; Pedersen, H. Matching Precursor Kinetics to Afford a More Robust CVD Chemistry: A Case Study of the C Chemistry for Silicon Carbide Using SiF4 as Si Precursor. J. Mater. Chem. C 2017, 5 (23), 5818-5823. https://doi.org/10.1039/C7TC00138J.

(34) Derudi, M.; Polino, D.; Cavallotti, C. Toluene and Benzyl Decomposition Mechanisms: Elementary Reactions and Kinetic Simulations. Phys. Chem. Chem. Phys. 2011, 13 (48), 21308. https://doi.org/10.1039/c1cp22601k. 